\title{
Study of Dynamic Viscosity and Density of Aprotic Solvents for Lithium - ion Batteries
}

\author{
M. Frk, J. Maca and Z. Rozsivalova \\ Department of Electrical and Electronic Technology \\ Brno University of Technology \\ Technicka 3058/10, 61600 Brno (Czech Republic) \\ Phone number: +420 54114 6127, Fax number: +420 541146147 \\ e-mail: frkmar@feec.vutbr.cz, macaj@feec.vutbr.cz, rozsiva@ $\underline{\text { feec.vutbr.cz }}$
}

\begin{abstract}
The article deals with description of rheological properties of solvents for electrolytes of lithium-ion accumulators. Solvents mixture of dimethyl sulfone and sulfolane at different volume ratios and with a lithium salt (LiClO4) appear as potentially suitable electrolyte. The aim of this experiment is to investigate the rheological properties, particularly density and dynamic viscosity, of solvents with lithium salt in temperature dependence and to find the optimal composition of the electrolyte from the perspective of achieving the lowest dynamic viscosity and better electrical conductivity because both quantities are closely related in accordance with Walden's rule. The vibration method is used to determine the values of dynamic viscosity.
\end{abstract}

\section{Key words}

Viscosity, Density, Aprotic electrolytes, Solvents

\section{Introduction}

Lithium-ion accumulators are among the power sources suitable, especially for the mobile applications, medical devices and electric vehicles. Rheological properties description of the electrolytes is one of the most important non-electrical physical quantities. These properties, in particular the value of dynamic viscosity, are decisive for the selection of suitable electrolyte solvents usable in lithium-ion accumulators. Solvents mixture of dimethylsulfone and sulfolane with a lithium salt (in particular case $\mathrm{LiClO}_{4}$ ) appear as potentially suitable electrolyte [1], [2]. The resulting ratio of the components depends on the desired properties to be achieved.

\section{Used Solvents}

Sulfolane from structure are to sulfur atom with a double bond bounded two atoms of oxygen and a carbon ring composed from four carbon atoms. The sulfur - oxygen bond is polar which enables a good dissolving in water (is completely miscible with water). The carbon ring is nonpolar so it is possible blend with water and hydrocarbons. Sulfolane is used as an industry solvent and for purification of natural gas and the most used solvent for aromatics purification [1], [2].

Dimethyl sulfone aka. methylsulfonylmethane (MSM), is an organic sulphur compound, it is a white crystalline solid at room conditions. Dimethyl sulfone is used in high temperature industry for organic and inorganic as extraction and reaction solvent, metal and fungicide treatment. Selected properties of used solvents are shown in Table 1.

Table I. - Selected properties of used solvents

\begin{tabular}{|c|c|c|c|c|}
\hline Solvent & $\begin{array}{c}\text { Density } \\
\left(\mathrm{kg} \mathrm{m}^{3}\right)\end{array}$ & $\begin{array}{c}\text { Viscosity } \\
(\mathrm{mPa})\end{array}$ & $\begin{array}{c}\text { Permittivity } \\
(-)\end{array}$ & $\begin{array}{c}\text { Melting } \\
\text { point } \\
\left({ }^{\circ} \mathrm{C}\right)\end{array}$ \\
\hline $\begin{array}{c}\text { Dimethyl } \\
\text { sulfone }\end{array}$ & 1450 & $\begin{array}{c}1.14 \\
\left.\text { (at } 123^{\circ} \mathrm{C}\right)\end{array}$ & 48 & 110.0 \\
\hline Sulfolane & 1261 & $\begin{array}{c}10.07 \\
\left(\text { at } 30^{\circ} \mathrm{C}\right)\end{array}$ & 44 & 27.5 \\
\hline
\end{tabular}

Solvents mixture of dimethylsulfone and sulfolane with a lithium salt (in particular case $\mathrm{LiClO}_{4}$ ) appear as potentially suitable electrolyte. The resulting ratio of the components depends on the desired properties to be achieved [4], [5]. The dependence of dynamic viscosity in a wide temperature range is observed to ensure optimal electrical properties. Dynamic viscosity is closely related to electrical conductivity in accordance with Walden's rule.

\section{Physical Quantities and Measurement Method}

\section{A. Dynamic viscosity}

Viscosity (dynamic or kinematic) is a characteristic property of liquid and it expresses the rate of internal fluid friction that occurs at mutual motion of parallel to each other adjacent layers. It is closely linked with the internal 
a)

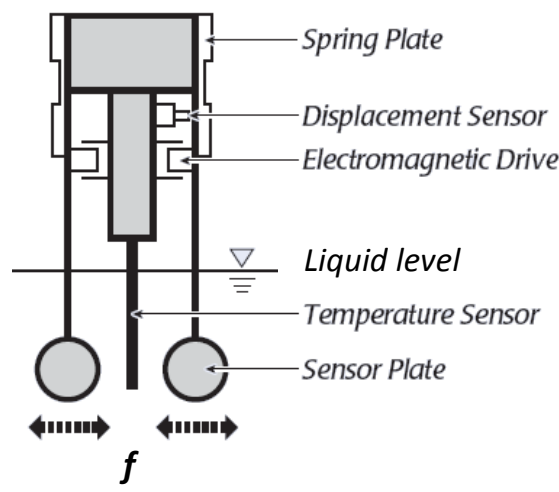

b)

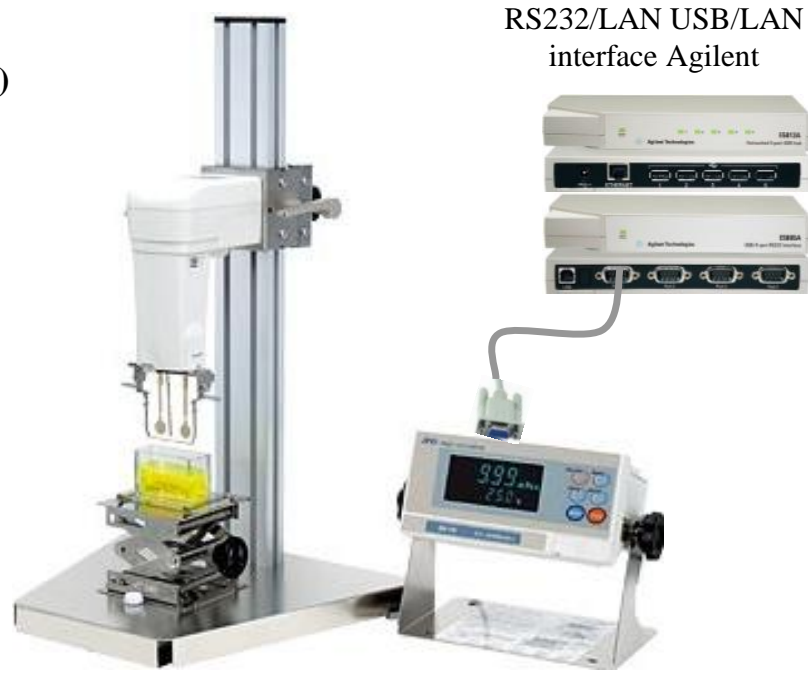

Fig. 1. a) Scheme and the physical principle of vibration viscometer A\&D SV10 [3] b) connection of the viscometer to the Internet

structure of liquids. The course of viscosity varies considerably with temperature. The temperature dependence has always decreasing character which is possible in most cases to express by the empirical Arrhenius mathematical function in the form

$$
\eta=A \cdot e^{\frac{b}{T}}
$$

where $A$ is a characteristic material constant dependent on the frequency of thermal vibration and on distance of individual liquid molecules (sometimes referred to as the viscosity $\eta_{\infty}$ at high temperature $T \rightarrow \infty$ ) and physical quantity $b$ is equal $b=E_{A} / R$ ( $E_{A}$ is the flow activation energy and $R$ is universal gas constant). This relation also often used to represent experimental viscosity data for pure fluid and fluid mixtures solutions [6], [7].

The vibration method was used to determine the values of dynamic viscosity. The general principle of viscosity measurement method consists in the transfer of current, required for keeping constant frequency and amplitude of the vibrations of the sensor plates immersed in the observed liquid, on the apparent viscosity. Viscometer A\&D SV series composed of two thin sensor plates with gold surface treatment that are driven with electromagnetic force at the same frequency by vibrating at constant sine-wave vibration in reverse phase like a tuning-fork. The electromagnetic drive controls the vibration of the sensor plates to keep in constant amplitude (see Figure 1a). The driving electric current, which is exciting force, will be detected as the magnitude of viscosity produced between the sensor plates and the sample fluid. The coefficient of viscosity is obtained by the correlation between the driving electric current and the magnitude of viscosity. Conversion of apparent viscosity $\eta_{a p}$ on dynamic $\eta$ is conditioned by knowledge of the sample density.

\section{B. Density}

Analytical balance Ohaus Explorer EX223 with extension kit for measuring the density of solid and liquid materials (see Figure 2a), based on the principle of Archimedes was used to determine the density of each solution. The density determination kit includes calibrated sinker (see Fig. 2b) of defined volume (in this case $\left.V=10,000 \pm 0,005 \mathrm{~cm}^{3}\right)$, whose mass is set in the air $\left(m_{1}\right)$ and subsequently in the observed solution $\left(m_{2}\right)$ of the desired temperature. The formula for calculating the density of a liquid $\rho_{l i q}$ can be derived from the resultant force $F$ acting on the immersed sinker (see Fig. 2c) in the liquid and takes the form

$$
\rho_{\text {liq }}=\frac{m_{1}-m_{2}}{V}+\rho_{\text {air }},
$$

that respects the measured data, including the effects of air density $\left(0,0012 \mathrm{~g} \mathrm{~cm}^{-3}\right)$.

\section{Sample preparing}

The samples of electrolyte were prepared with different concentration ratios of solvents as a sulfolane and dimethyl sulfone (both from Sigma-Aldrich Corporation). The amount of dimethyl sulfone in sulfolane varied from $0 \%$ volume percent to the saturation of dimethyl sulfone at $17 \%$ volume percent. The lithium salt $\mathrm{LiClO}_{4}(1 \mathrm{M}$ concentration) was added and dissolved in to the all samples.

Into the beaker with sulfolane heated to $40{ }^{\circ} \mathrm{C}$ was added dimethyl sulfone (under the room conditions solid state). The weight of dimethyl sulfone was calculated from knowledge of the density values and the required volume. The resulting mixture was heated with hot air at 115 to $120{ }^{\circ} \mathrm{C}$ (at temperature above the melting point of dimethyl sulfone). After melting and mutual mixing of solution components, it was added a defined amount of lithium salt $\left(\mathrm{LiClO}_{4}\right.$ - lithium perchlorate) in to the 
a)

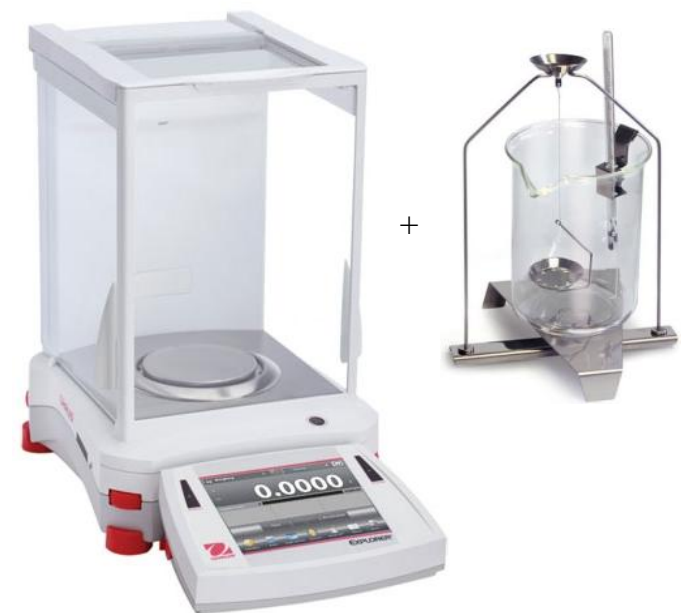

b)

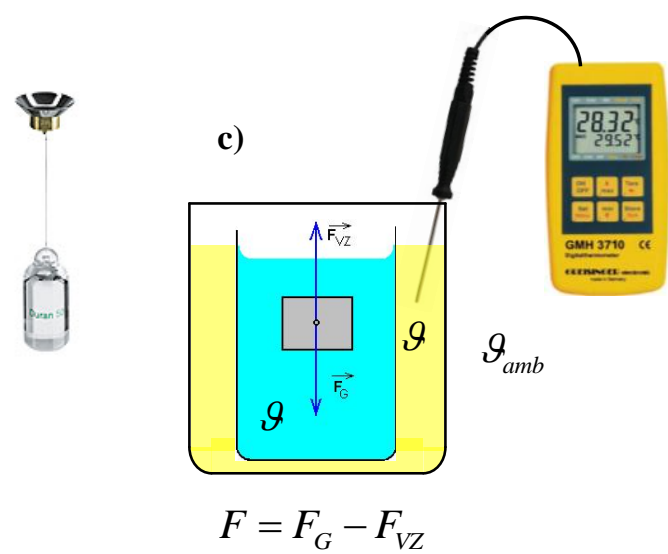

Fig. 2. a) Instrumentation Ohaus including density determination kit, b) detail of glass sinker, c) the physical principle and the thermal stabilization of the solution in the course of experiment

mixture. The resulting sample of solution was blended in a closed vessel on magnetic stirrer for another 24 hours.

\section{A. Density determination of solutions}

Densities of investigated, variously concentrated solutions were monitored in the temperature range $5-90{ }^{\circ} \mathrm{C}$ with a step of approximately $20{ }^{\circ} \mathrm{C}$. From the obtained and approximated temperature dependences of density it is possible, among other things, to determine the coefficients of volume expansion of solutions which in liquid materials are not generally negligible. To achieve the lower temperature range, respectively higher temperature range than the ambient temperature, the temperature chamber CLIMACEL 111 was used, in which the temperature stabilization of all solutions samples proceed. The beaker with solution was immersed in the vessel with synthetic organic ester fluid to ensure sufficient thermal stability in the course of density measurement. The digital thermometer GREISINGER 3710 with a probe Pt100 Class A was used to determine the actual temperature of solutions (see Fig. 2c).

The volumetric changes of the solution, respectively calculated density values in the temperature dependence were approximated by the mathematical function in the form,

$$
V=V_{20}(1+\beta \Delta \vartheta), \text { resp. } \rho=\frac{\rho_{20}}{(1+\beta \Delta \vartheta)},
$$

which takes into account only the linear coefficient of volume expansion $\beta$. Quadratic term which is very small is applied in the case of higher temperature differences $\Delta \vartheta$ and therefore is neglected here. Temperature dependencies of the density of the solutions with limit DMSO2 concentrations ( 0 and $17 \%$ volume percent) are shown in Fig. 3. The displayed curves create a sector. Within this area, the dependencies are situated for solutions with other concentrations, but for greater lucidity, are not shown graphically.

The calculated values of the coefficient of volume expansion $\beta$ and density of the solutions $\rho_{20}$ at $20{ }^{\circ} \mathrm{C}$ are listed in Table II with the volume percentage DMSO2 as a parameter.

\section{$B$. Dynamic viscosity measurement of solutions}

The automated laboratory workplace was assembled to measure rheological properties of fluids in temperature range. Also, Agilent graphical language environment VEE Pro was used for the communication between computer and viscometer A\&D SV 10 and analytical balance Ohaus Explorer Ex223. Serial communication interfaces of viscometer and bath thermostat were connected to the USB/RS232 Interface Agilent E5805A whose USB output was directly interconnected to the Networked LAN/USB Hub Agilent E5813A that provides access to the Internet (see Figure 1b). In this way, it is possible to remotely control the instruments which are equipped with serial interface RS232 only over Internet.

The measured apparent viscosity values $\eta_{a p}$ were converted to dynamic viscosity for all measured temperature according to the relationship

$$
\eta(T)=\frac{\eta_{a p}}{\rho_{r e l}(T)},
$$

where $\rho_{\text {rel }}$ is the relative density of the sample, i.e. the value of the density related to the unit density to which the instrument is calibrated. 
Table II. Selected physical properties of the investigated solutions at various concentrations

\begin{tabular}{|c|c|c|c|c|c|c|c|}
\hline vol\% DMSO2 & $0 \%$ & $3 \%$ & $6 \%$ & $9 \%$ & $12 \%$ & $15 \%$ & $17 \%$ \\
\hline$\rho_{20}\left(\mathrm{~g} \cdot \mathrm{cm}^{-3}\right)$ & 1,315 & 1,315 & 1,313 & 1,310 & 1,310 & 1,309 & 1,307 \\
\hline$\beta\left(10^{-4} \mathrm{~K}^{-1}\right)$ & 6,93 & 6,86 & 6,86 & 6,89 & 7,17 & 6,58 & 6,51 \\
\hline
\end{tabular}

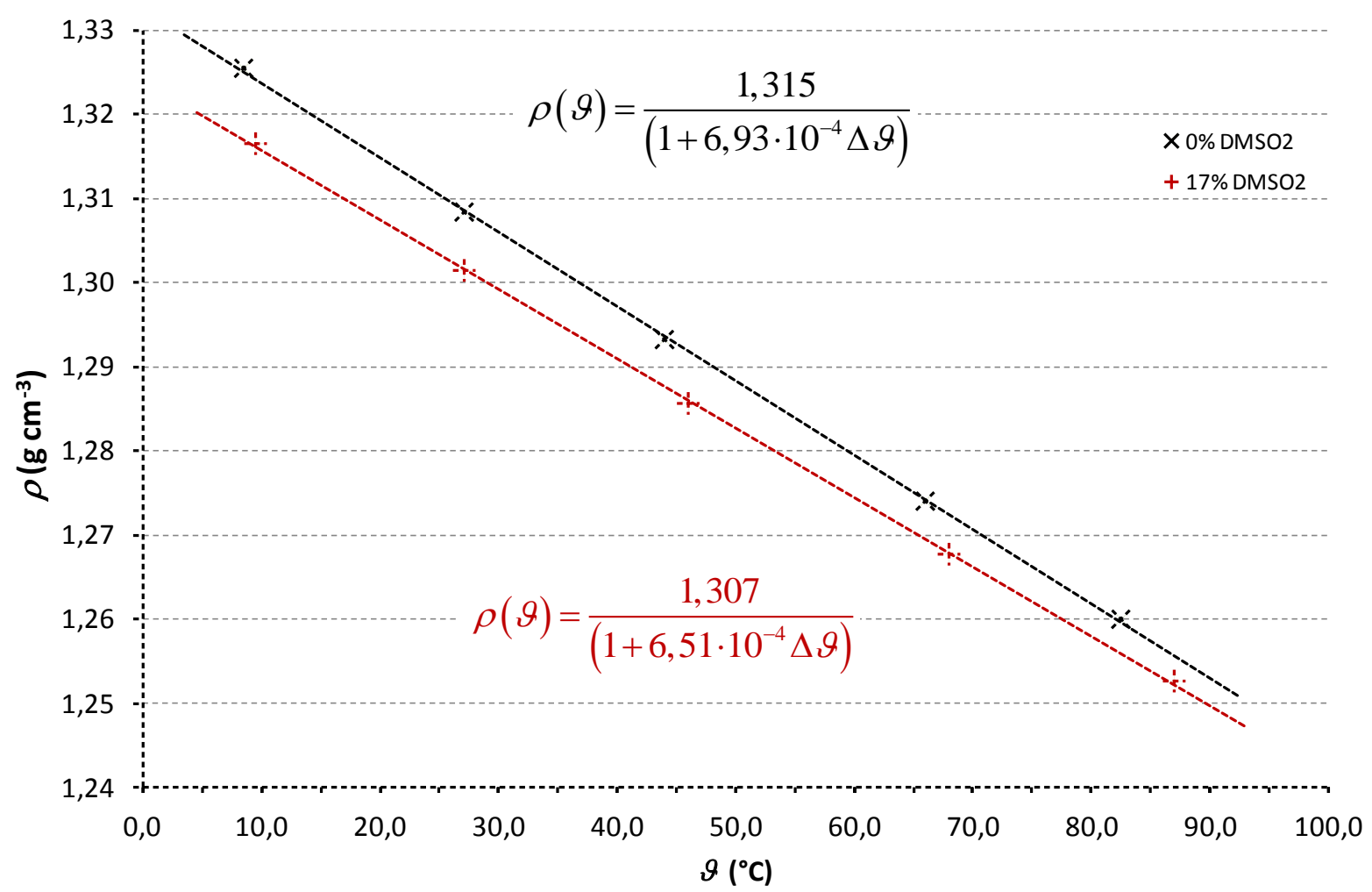

Fig. 3. The temperature dependencies of the density of solution

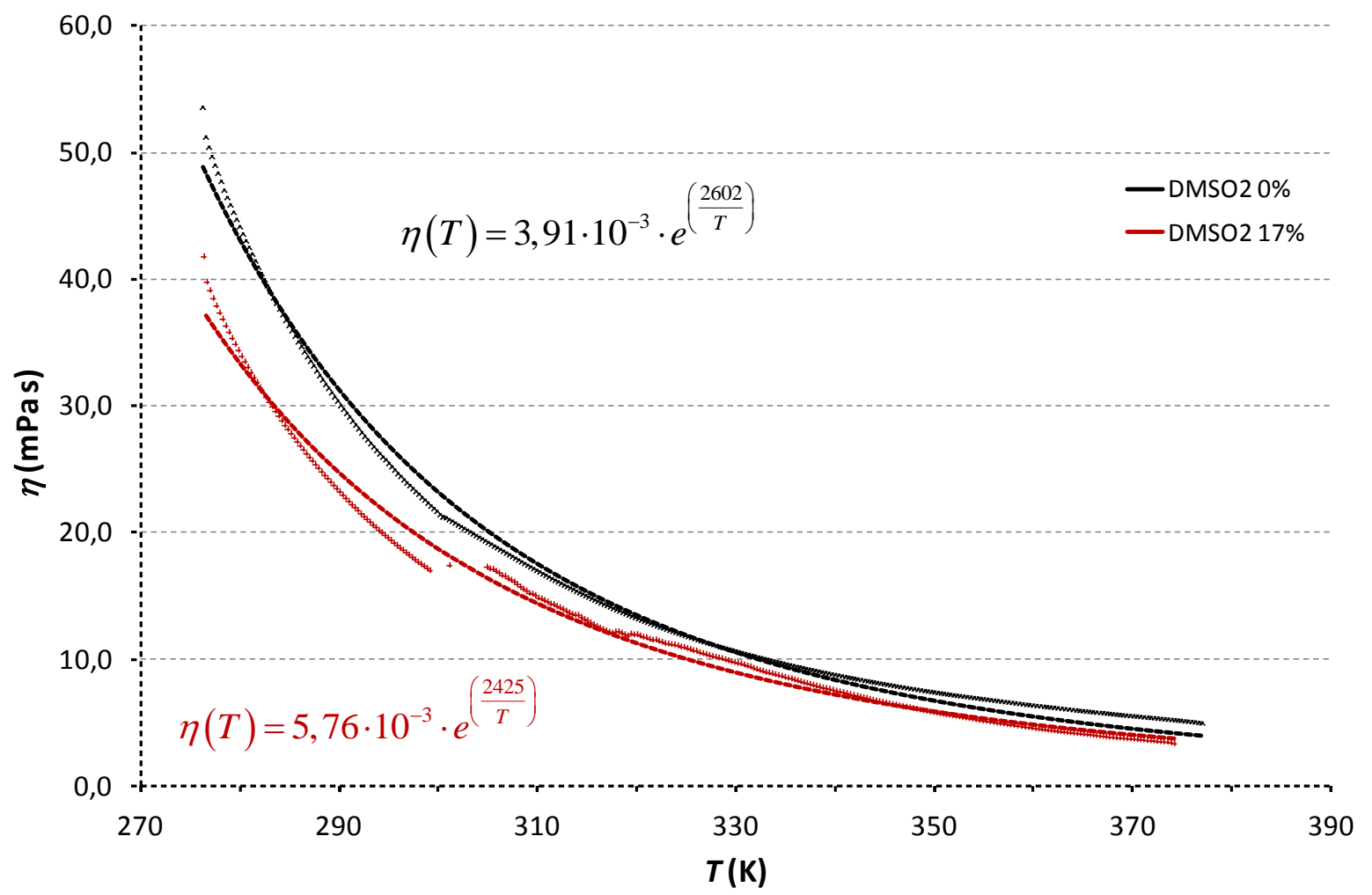

Fig. 4: The temperature dependencies of the dynamic viscosity 
Temperature dependencies of the dynamic viscosity of the solutions with limit DMSO2 concentrations (0 and $17 \%$ volume percent) again are shown in Figure 4 (discreet points). As one can see from this figure, the viscosity of solutions monotonically decreases with increasing temperature. Temperature dependencies of viscosity were approximated by the Arrhenius function using the least squares method and the resultant courses are plotted graphically in Figure 4 (solid line) including relevant equations.

\section{Conclusion}

Theoretical information about vibration method of viscosity measurement was summarized and initial results were published in the article. Dynamic viscosity of seven solutions of dimethyl sulfone and sulfolane at different volume ratios $(0,3,6,9,12,15$ and 17 vol \% DMSO2) and with a lithium salt $\left(\mathrm{LiClO}_{4}\right)$ have been measured with vibration techniques in temperature range from 275 to 375 $\mathrm{K}$. All of these solutions have approximately the same value of the coefficient of volume expansion which takes the value around 6,90.10-4 $\mathrm{K}^{-1}$. Solution (17 vol \% DMSO2) exhibited the lowest value of the dynamic viscosity in whole temperature range and appears as potentially more suitable for electrolyte from the perspective of rheological properties. The values of flow activation energy will be calculated from the temperature dependencies of dynamic viscosity in the course of other experimental activities. Subsequently it will be examined the behaviour of solutions in DC and AC electric field to obtain the frequency dependencies of relative permittivity and electrical conductivity which is closely related to dynamic viscosity in accordance with Walden's rule.

\section{Acknowledgement}

This work was supported by the grant FEKT-S-11-7 "Materiály a technologie pro elektrotechniku", grant GAČR P102/10/2091, „Increase the safety of lithium-ion batteries" and project CZ.1.07/2.3.00/20.0103 "Support for human resources and transfer of knowledge in conditions of international cooperation of research teams“.

\section{References}

[1] A. Abouimrane, I. Belharouak and K. Amine, Sulfolane-based electrolytes for high-voltage Li-ion batteries, in Electrochemistry- Communications 11 (2009), pp. 1073-1076

[2] Y. Marcus, The Properties of Solvents, John Wiley \& Sons Ltd, Chichester (1998), p. 399.

[3] A\&D Company Limited. SV-A Series Users' Handbook Version 1.13E. (2009).

[4] Reid, R.C., Prausnitz, J.M. \& Poling, B.E. The Properties of Gases and Liquids, 4th edn. NY: McGaw-Hill, (1987).

[5] A. L. Horvath. Handbook of Aqueous Electrolyte Solutions: Physical Properties, Estimation Methods and Correlation Methods, England: Ellis Horwood West Sussex, Ellis Horwood (1985).

[6] J. Águila-Hernández, A. Trejo, B. García-Flores, R. Molnar. Viscometric and volumetric behaviour of binary mixtures of sulfolane and N- methylpyrrolidone with monoethanolamine and diethanolamine in the range 303-373 K, in Fludi Phase Equilibria 267 (2008), pp. 172-180

[7] D. Brouillette, G. Perron, J. Desnoyers. Effect of viscosity and volume on the specific conductivity of lithium salts in solvent mixtures, in Electrochemica Acta 44 (1999), pp. 4721-4742. 